\title{
Thorium-derived dust fluxes in the Pacific: examining seawater, particle and sediment-based estimates
}

ERIN BLACK ${ }^{1}$, ROBERT ANDERSON ${ }^{2}$, R. LAWRENCE EDWARDS $^{3}$, CHRISTOPHER T HAYES ${ }^{4}$, XIANGLEI LI $^{3}$, MARTY FLEISHER ${ }^{1}$, FRANK PAVIA ${ }^{5}$, NEIL A REDMOND ${ }^{4}$ AND PETER SCHROEDL ${ }^{3}$

${ }^{1}$ Lamont-Doherty Earth Observatory

${ }^{2}$ Columbia University

${ }^{3}$ University of Minnesota

${ }^{4}$ University of Southern Mississippi

${ }^{5}$ California Institute of Technology

Presenting Author: erinb@1deo.columbia.edu

Thorium-derived dust fluxes are important for the quantification of modern oceanic inputs, as well as a vital component for the reconstruction of paleoclimate records. Primordial Thorium-232 ( $1 \frac{1}{2} \sim 14 \mathrm{Ga}$ ) tracks inputs that originate from lithogenic sources, including aerosol dust. Thorium-230 $(\mathrm{t}$ $1 / 2 \sim 76 \mathrm{ka}$ ) is produced by the decay of Uranium-234 at a known rate within the ocean. These isotopes can be used in tandem to estimate the atmospheric delivery to the water column and the transport of this material through the water column. Emerging techniques have allowed estimates of dust flux to be determined utilizing filtered seawater samples, size-fractionated particulate material, or sediment cores.

Dust flux profiles derived from seawater and particulate samples taken during the GP15 GEOTRACES campaign in 2018 (Alaska to Tahiti) reflect similar processes and patterns to those observed during prior Pacific efforts. ${ }^{230}$ Th-normalized fluxes of ${ }^{232} \mathrm{Th}$ increase with depth in the upper $\sim 500 \mathrm{~m}$ and remain relatively constant between $\sim 500 \mathrm{~m}$ and $3000 \mathrm{~m}$. These consistent mid-water values are taken to be representative of mean annual dust flux to the region and show the expected higher values in the northern hemisphere compared to the southern hemisphere and Equatorial waters. Interestingly, ${ }^{230} \mathrm{Th}$ normalized fluxes of ${ }^{232} \mathrm{Th}$ from nearby sediment core tops are three to five times higher than the dust flux estimates derived from intermediate water samples. This suggests that core tops do not represent modern dust fluxes, although alternative interpretations will be discussed. 